\title{
Gaúchos roraimados: uma identidade interessada, interesseira e interessante
}

\section{Gaúchos roraimados: una identidad interesada, intereseira e interesante}

\section{Gaúchos roraimados: an identity interested, interesseira and interesting}

\author{
Tatiana Costa Rosa ${ }^{1}$ \\ Leila Adriana Baptaglin²
}

\begin{abstract}
Resumo
O presente artigo visa mostrar como os gaúchos que moram em Roraima percebem sua identidade enquanto sujeitos fora do seu local de origem, levando em consideração os demais elementos que contribuem para o processo do hibridismo identitário. Assim, este estudo se justifica pelo fato de aliar teoria e prática, pois aborda aspectos teóricos acompanhado de os resultados práticos obtidos por meio de uma entrevista realizada com dez gaúchos roraimados. Por meio das respostas dos entrevistados pode-se constatar que a maioria dos sujeitos entrevistados possui a noção de que não fazem parte apenas da cultura Rio-Grandense, de uma cultura, e sim das duas, ou mais, adotando em suas vidas palavras, costumes e aspectos particulares de cada uma, tornando-se assim um exemplo de sujeitos com identidades multifacetadas.
\end{abstract}

Palavras-Chave: Gaúchos Roraimados; Hibridismo identitário; Identidade.

\section{Resumen}

El presente artículo visa mostrar como los gaúchos que viven en Roraima perciben su identidad mientras sujetos fuera de su local de origen, llevando en consideración los demás elementos que contribuyen para el proceso del hibridismo identitário. Así, este estudio se justifica por el hecho de aliar teoría y práctica, pues aborda aspectos teóricos acompañado de los resultados prácticos obtenidos por medio de una entrevista realizada con diez gaúchos roraimados. Por medio de las respuestas de los entrevistados se puede constatar que la mayoría de los sujetos entrevistados posee la noción de que no forman parte sólo de la cultura Río-Grandense, de una cultura, y sí de dos, o más, adoptando en sus vidas palabras, costumbres y aspectos particulares de cada una, haciéndose así un ejemplo de sujetos con identidades multifacetadas.

Palabras claves: Gaúchos Roraimados; La hibridación de identidad; Identidad.

\begin{abstract}
The present article visa present like the gaúchos that live in Roraima perceive his identity while subject out of his venue of origin, carrying in consideration the other elements that contribute for the process of the identitary hybridity. Like this, this study justifies by the fact of unit theory and practical, as it tackles theoretical aspects jointly with the practical results obtained by means of an interview made with ten roraimados gaúchos. By means of the answers of the interviewed can ascertain that the majority of the roraimados gaúchos interviewed

\footnotetext{
${ }^{1}$ Arquivista do Instituto Federal de Roraima (IFRR) - Campus Boa Vista Centro. Mestranda em Letras pela Universidade Federal de Roraima (UFRR) - Linha 02: Literatura, Artes e Cultura, com ênfase em Patrimônio Cultural - Documental. Especialista em Gestão de Arquivos pela Universidade Federal de Santa Maria (UFSM), 2014. Graduada em Arquivologia pela UFSM, 2013, e Graduada em Marketing pela Faculdade de Tecnologia Internacional do Grupo Uninter (FACINTER), 2010. E-mail: tatyrosaa@ gmail.com.

${ }^{2}$ Doutora em Educação pela Universidade Federal de Santa Maria- UFSM (2011-2014). Mestre em Educação e, Mestre em Patrimônio Cultural ambos pela UFSM (2008-2010). Especialista em Gestão Educacional-UFSM (2007-2008). Graduada em Desenho e Plásticas- Bacharelado pela Universidade Federal de Santa Maria (2006), Graduada em Desenho e Plásticas-Licenciatura pela Universidade Federal de Santa Maria (2007). Professora/pesquisadora Auxiliar 40hs DE do Curso de Artes Visuais/Licenciatura da UFRR. E-mail: leila.baptaglin@ufrr.br.
} 
possesses the notion that they do not form part only of the culture Rio-Grandense, of one culture, and yes of the two, or more, adopting in his lives words, habits and particular aspects of each one, doing like this an example of subjects with identities multifaceted.

Keywords: Gaúchos Roraimados; Identitary hybridity Identity.

\section{Introdução}

A identidade de uma região é percebida, geralmente, por suas tradições culturais. Desta forma, a concepção da identidade individual dos sujeitos que compõem uma determinada região é considerada por muitos autores como uma identidade híbrida, isto é, um sujeito com múltiplas identidades em contínuo processo de construção.

Composta e influenciada por diversos fatores como: a linguagem, a língua, o léxico, as relações sociais, culturais, de poder, de negociação, o sentimento de pertencimento; a concepção da diferença e a identidade tornam-se interessantes de serem estudadas, por não ser algo engessado, fixado nos sujeitos.

No que diz respeito ao Estado de Roraima, é perceptível que passou por transformações ao longo dos anos. Composto por uma população diversificada, o Estado recebe migrantes de várias partes do Brasil ${ }^{3}$. A capital do Estado de Roraima é Boa Vista, onde se concentra principalmente o militarismo e funcionalismo público do Estado. De acordo com Botelho (2009), a capital é onde se encontra a melhor infraestrutura e maior produção de bens e serviços públicos, privados e culturais de Roraima. Por esta razão, a maior parte da população do Estado se concentra na capital.

Ao longo do processo de ocupação ocorreu o fluxo migratório no Estado e principalmente em sua capital, recebendo pessoas de países vizinhos e de diversas regiões brasileiras, principalmente do Sul e Nordeste, que vieram em busca de melhores condições profissionais e de vida. Isto possibilitou que Roraima se tornasse um Estado híbrido social e culturalmente, resultando em uma diversidade linguística e cultural na região, consequentemente intervindo na identidade de Roraimenses e Roraimados ${ }^{4}$.

Nesta pesquisa destacam-se os gaúchos, por serem um grande número de sujeitos que residem em Roraima e que, mesmo distantes do Rio Grande Sul, perpetuam fortemente suas tradições. Isso pode ser explicitado haja vista a existência, no Estado, de um Centro de

\footnotetext{
${ }^{3}$ De acordo com o Instituto Brasileiro de Geografia e Estatística (IBGE), até o ano de 1970 o crescimento populacional de Roraima obedecia a media do Brasil. Entretanto, entre os anos de 1980 e 1990 houve um aumento significativo no crescimento populacional, passando de 80 mil habitantes para 217 mil.

${ }^{4} \mathrm{O}$ termo Roraimado é usualmente utilizado no Estado de Roraima para denominar sujeitos que migraram de outros lugares e residem em Roraima.
} 
Tradições Gaúchas (CTG - Nova Querência), o qual é conhecido e frequentado por Roraimenses, Roraimados e turistas. O CTG situa-se na capital, Boa Vista, e é um local aberto ao público onde, quando ocorrem eventos, festas e apresentações é possível observar a diversidade linguística, cultural e identitária existente em Roraima.

Partindo destes pressupostos acima mencionados, tem-se o seguinte questionamento como problema de pesquisa: "Como os gaúchos roraimados percebem sua identidade enquanto sujeitos fora do seu local de origem?". Tal problema nos remete ao objetivo geral de investigação voltado a apresentar aspectos acerca da identidade dos gaúchos roraimados. Para isso, temos como objetivos específicos: verificar a interferência do tempo e do espaço na identidade dos gaúchos roraimados; investigar elementos que influenciam na identidade dos gaúchos roraimados; compreender o hibridismo identitário sob uma ótica teórico-prática.

Pelo fato de um sujeito sair do Rio Grande do Sul e vir morar em Roraima, já pode ser considerado um sujeito com uma identidade híbrida, pois conscientemente ou inconscientemente acaba adotando alguns aspectos da língua e da cultura na qual está inserido fisicamente. Contudo, tem-se conhecimento disto por meio de estudos com embasamento teórico, a exemplo dos autores como: Homi Bhabha, Nestor Garcia Canclini, Stuart Hall, Zygmunt Bauman, entre outros, nos faltando muitas vezes o embasamento prático para defender esta concepção de sujeitos com identidades multifacetadas.

Deste modo, a realização desta pesquisa justifica-se pelo fato de aliar teoria e prática, investigando-se, através da realização de uma entrevista com gaúchos roraimados como eles se percebem enquanto sujeitos, fora de seu local de origem, contextualizando com os demais fatores que também influenciam na identidade. Unindo aspectos teóricos e resultados práticos relevantes sobre a construção de uma identidade que é interessada, interesseira e torna-se interessante ao ser vista pela ótica teórico-prática.

Para concretizar esta pesquisa serão apresentados na sequência alguns tópicos, tais como: a fundamentação teórica; metodologia utilizada; análise e discussão dos resultados obtidos; considerações finais e as referências.

\section{Identidade e suas facetas}

Entre os diversos autores que tratam do tema, pode-se observar que é difícil chegar a uma única definição de identidade. Contudo, é possível constatar que em sua maioria, defendem a ideia de que a identidade dos sujeitos pós-modernos é multifacetada, inacabada e instável, sendo fortemente influenciada por mudanças culturais, como com o advento da globalização, por exemplo. 
Bauman (1998) aponta que não são apenas as mudanças culturais que ocorrem na sociedade contemporânea, e sim que a sociedade também sobre diretamente em suas vidas os efeitos produzidos pelas mudanças, seja nos afetos, relacionamentos, sentimentos, bem como em suas identidades. Indo ao encontro de Bauman, Hall (2006), afirma que com a globalização as identidades estão em crise, pois a diversidade cultural torna-se mais visível perante a sociedade, resultando em identidades em transição, conflitantes e negociáveis.

Hall (2006) defende que com a globalização houve o reforço das identidades, o interesse pelo "local"; e que este é um processo desigual, devido ao fato de não ocorrer de forma igual em todos os lugares. Ele estabelece três consequências possíveis da globalização para a identidade, são elas: as identidades nacionais estão se desintegrando; algumas identidades nacionais e locais estão se reforçando como resistência à globalização; e as identidades nacionais estão em declínio, dando origem a identidades híbridas.

Canclini (1997) define que a identidade latina, por exemplo, sempre foi uma construção híbrida. Onde a confluência das culturas europeias, indígenas e africanas influenciaram a identidade latino-americana, que foi formada por processos de hibridação. $\mathrm{O}$ termo hibridação é definido pelo autor como: "processos socioculturais em que estruturas e práticas, que existiam de forma separada, se combinam para gerar novas estruturas, objetos ou práticas" (Canclini, 2000, p. 2).

No que diz respeito ao sujeito pós-moderno, Hall (2006) considera que este é constituído socialmente e culturalmente, não mais visto como um ser unificado, mas sim híbrido, fragmentado, com identidades multifacetadas, que o constituem e que estão constantemente sendo construídas, desconstruídas e reconstruídas.

Assim, a (re)/(des)construção identitária ocorre por meio da interação e comunicação entre os sujeitos, dentro de um determinado contexto, geralmente relacionado a algum interesse. Para compreendermos a identidade, e como ocorre o hibridismo identitário se faz necessário compreendermos que as identidades, tanto as individuais, quanto as coletivas, são compostas por alguns fatores que as influenciam.

\subsection{Fatores que influenciam a identidade}

Existem alguns fatores que fazem parte e contribuem com a identidade e o processo do hibridismo identitário, entre eles: a linguagem, a língua, as relações sociais, culturais, de poder, o sentimento de pertencimento, negociação, concepção de diferenças, etc.

O ser humano traz consigo uma linguagem, que é como uma bagagem, faz parte naturalmente dele e o identifica. O indiano Rajagolapan, ao ser questionado em Xavier e 
Cortez (2003, p.180), afirma que "A linguagem não é mais instrumento de coisa de alguma. A linguagem é muito mais que isso. Linguagem somos nós”. O que demonstra que a linguagem está sempre presente no homem, estando ele ciente disto, ou não. Contudo, em meio às relações sociais e de poder o homem conscientiza-se mais da importância da linguagem e da língua para o convívio social e para se destacar frente aos outros.

Para Freitas (2007, p.105), “A língua é apenas um dos elementos mais apontados, e cobrados, como característica de identidade", porém, vale salientar que não é o único. A língua contribui para a construção de uma identidade, e ambas não são algo engessado.

$\mathrm{O}$ que nos remete a repensar a língua em função de algumas categorias e consequências, conforme destacam César e Cavalcanti (2007, p.60):

Torna-se, por isso, necessário repensar a língua em função de categorias: os diversos tempos ao mesmo tempo, os corpos em suas múltiplas interações, emblemas cambiantes, fragmentados, contraditórios, tendo como consequências identidades contraditórias, constituídas num mundo de mesclagem cultural, linguística, onde as correntes migratórias e os movimentos sociais procuram definir outras relações.

Indo ao encontro de César e Cavalcante, Lagares (2010, p. 131-132) vai além, e aponta que não devemos compreender a língua de forma reduzida "a um dicionário e a uma gramática". E sim, que deve-se trabalhar a língua nas entrelinhas, apoiando-se na língua escrita, por ser uma "tangibilidade" da língua gravada em palavras, documentada, em conjunto com as formas e as expressões linguísticas, que nem sempre encontram-se em dicionários.

Neste sentido, vale refletir sobre o estudo lexical, o qual Vilela (1995, p. 13) afirma quando observado numa perspectiva comunicativa "é o conjunto das palavras por meio das quais os membros de uma comunidade linguística se comunicam entre si”. Através de um estudo lexical é possível ter conhecimento de diversos aspectos de um sujeito e de uma sociedade. De acordo com Sapir (1980, p. 45):

O léxico completo de uma língua pode se considerar, na verdade, como o complexo inventário de todas as ideias, interesses e ocupações que açambarcam a atenção da comunidade; e, por isso, se houvesse à nossa disposição um tesouro assim cabal da língua de uma dada tribo, poderíamos daí inferir, em grande parte, o caráter do ambiente físico e as características culturais do povo considerado.

O estudo de determinado léxico, contribui para a compreensão de aspectos do passado e do presente de uma cultura, de uma sociedade, e de uma identidade, que pode ser investigada ao estar registrada por meio de palavras que possuem algum significado para o sujeito. 
No que diz respeito à identidade, Rutherford (1990, p.19-20 apud Woodward, 2000, p. 19) afirma que ela “...marca o encontro de nosso passado com as relações sociais, culturais e econômicas nas quais vivemos agora $[\ldots] . . . ”$, deste modo, a identidade está sempre em movimento, aliando o que fomos ao que somos e seremos, com base em relações sociais, culturais, econômicas e de poder vivenciadas por cada sujeito.

Identidade é também pertencimento e negociação. Bauman (2005, p. 17), afirma que o "pertencimento" e a "identidade" não têm a solidez de uma rocha, não são garantidos para toda a vida, são bastante negociáveis e revogáveis, e "a forma como o indivíduo representa os atores sociais", as decisões que o próprio indivíduo toma, os caminhos que percorre, a maneira como age e a determinação de se manter firme a tudo isso, são fatores cruciais tanto para o "pertencimento" quanto para a "identidade". Cada sujeito possui vivências, experiências particulares e se percebe de uma forma. Contudo, independente da trajetória, quase sempre acaba negociando e adotando uma identidade que mais convém para a ocasião, tendo como motivação: se encaixar, pertencer a um determinado grupo. Moldando-se conforme interesses, pessoais ou coletivos, tornando a identidade interessada, interesseira e interessante de ser estudada.

É difícil discutirmos identidade sem mencionarmos a diferença, pois a diferença está intimamente interligada à identidade, sendo que a identidade é simplesmente aquilo que se é: sou gaúcho, sou branco. Enquanto a diferença é aquilo que o outro é: ela é macuxi, ela é negra. Segundo Silva (2000, p.74), ambas possuem "uma relação de estreita dependência". Dependência esta que se estende até a linguagem, conforme ele salienta quando Silva define que identidade e diferença "são criadas por atos de linguagem", e inclusive a própria língua “não passa de um sistema de diferenças" (SILVA, p. 76-77, 2000).

Segundo Hall (2006), essas identidades híbridas são construídas dentro e não fora do discurso. E é necessário compreendê-las como foram produzidas em locais históricos e institucionais específicos, no interior de formações e práticas discursivas específicas, por estratégias e iniciativas específicas.

No que diz respeito ao Rio Grande do Sul, Luvizotto (2009, p. 11) afirma que:

O regionalismo sul-rio-grandense e suas expressões estão alicerçados em tradições e em conhecimentos obtidos pela convivência de diferentes grupos que contribuíram para a formação histórica e cultural do sul do país e para a construção de uma identidade comum, somados aos elementos históricos e sociológicos. Seus legados e sua tradição são transportados para as gerações seguintes, sujeitos às mudanças próprias de cada época e circunstância. 
Contudo, os sujeitos ao saírem do Estado do Rio Grande do Sul e partirem para outro local, no caso desta pesquisa, o Estado de Roraima, ocorre o movimento de "desenraizar e enraizar" (SOUZA, 2006, p.199), bem como uma manutenção da identidade destes sujeitos.

Pelo fato da identidade não ser necessariamente uma essência do sujeito, podendo ser construída, contraditória, inconsistente, inacabada e na maioria das vezes vinculada a relações de poder e negociação, cabe compreender como ocorre a manutenção da identidade individual, bem como, ocorre o desenraizamento e o enraizamento dos gaúchos roraimados. Ao analisar alguns aspectos como: o tempo que moram em Roraima, local de origem, se ainda visitam o Rio grande do Sul, a percepção de sotaque que os sujeitos têm, o léxico, os sentimentos despertados aos relembrar das culturas Rio-grandense e Roraimense, aliando-os aos elementos mencionados que influenciam na construção da identidade, é possível perceber e apresentar de forma mais especificada as características identitárias destes sujeitos.

\section{Caminhos da pesquisa}

A busca por alcançar os objetivos propostos nesta pesquisa percorreu uma série de caminhos, entre eles: o contexto em que os sujeitos da pesquisa estão inseridos, bem como a caracterização dos mesmos; os aspectos relacionados ao planejamento da pesquisa; método utilizado e a forma que o instrumento para coleta de dados foi elaborado, aplicado e analisado.

Os indivíduos deste estudo são dez gaúchos que moram no Estado de Roraima. Todos os sujeitos que responderam o instrumento disponibilizaram-se voluntariamente a participar da pesquisa, preenchendo inclusive o Termo de Consentimento Livre Esclarecido (TCLE). Definiu-se que todas as respostas seriam consideradas, respeitando a opinião do entrevistado, visto que as repostas dadas embasarão a reflexão e discussão ao longo do estudo.

O instrumento selecionado para a coleta de dados é uma entrevista semi-estruturada, considerando que "as narrativas orais se apresentam assim muito mais do que uma mera técnica de coleta de dados, transformando-se nos próprios dados" (FREITAS, 2007, p.109).

Utilizou-se a abordagem qualitativa, tendo em vista que segundo Neves (1996), esta deve ser adotada quando o pesquisador procura entender aspectos segundo a perspectiva do participante da situação estudada, e a, partir daí, situa sua interpretação dos dados levantados. Permite assim, verificar a relação da realidade, oportunizando uma interpretação indutiva por parte do pesquisador. A utilização desta abordagem é de suma importância para esta pesquisa, pois estimula o sujeito entrevistado a expor sua opinião livremente sobre o tema. Concomitantemente, adotou-se a abordagem quantitativa, que ainda segundo Neves (1996), serve para descrever e explicar fenômenos. Permite que os dados obtidos sejam mensurados 
em números, classificados e analisados. A utilização de ambos os métodos em conjunto, contribuem com a pesquisa e a pesquisadora, no sentido de que se obtenha uma melhor compreensão e exploração dos dados coletados, e consequentemente, uma melhor apresentação dos resultados obtidos.

A entrevista utilizada para a coleta de dados foi elaborada com o auxílio do referencial teórico e por meio de pesquisas em trabalhos referentes à temática identidade e linguagem. A entrevista apresenta sete questões prévias que visam auxiliar na busca em atingir os objetivos propostos, são elas: 1. Quanto tempo você mora em Roraima?; 2. De qual cidade do Rio Grande do Sul você é?; 3.Você ainda visita o Rio Grande do Sul, se sim, com que frequência?; 4. Percebe alguma diferença ou mudança em seu sotaque e/ou modo de falar quando está/estava no Rio Grande do Sul do que quando está em Roraima?; 5. Qual foi sua motivação para sair do Rio Grande do Sul?; 6. Se tivesse que resumir/apresentar o Rio Grande do Sul em 3 palavras e Roraima em 3 palavras quais seriam?, E Que sentimentos estas palavras despertam em você?; 7. Com qual cultura você mais se identifica atualmente? A Rio Grandense, a Roraimense, ambas, ou nenhuma? Por quê?.

As entrevistas foram aplicadas entre a segunda e terceira semanas do mês de outubro do ano de 2016. Antes de cada aplicação foi dada ao entrevistado uma breve explicação sobre o tema da pesquisa e entregue o termo de livre e esclarecido (TCLE) para assinatura. Com todos os sujeitos as entrevistas duraram cerca de 20 minutos. Considerando que esta pesquisa envolve seres humanos, optou-se por preservar suas respectivas identidades, nomeando-os como: sujeito 1, sujeito 2 , etc. As respostas foram analisadas quantitativamente, e qualitativamente, por meio da interpretação, comparação e discussão dos resultados obtidos.

\section{Análise e discussão dos resultados}

O tempo de convivência, morando e absorvendo a cultura Roraimense pode ter influência na identidade dos gaúchos roraimados, tornando-se assim importante, primeiramente, averiguar há quanto tempo os gaúchos entrevistados residem em Roraima, bem como o seu local de origem.

Quanto ao tempo que os sujeitos saíram do Rio Grande do Sul e vieram morar em Roraima as respostas variaram, sendo que dos 10 entrevistados: 2 moram em Roraima há 29 anos; 2 há 26 anos; 1 há 17 anos; 1 há 13 anos; 1 há 1 ano e 8 meses, 2 há 1 ano de 6 meses e 1 há 1 ano e 4 meses.

Conforme Souza (2006, p. 202-203), “O lugar de origem e o de adoção são duas coisas 
distintas, ainda que no momento da narrativa se cruzem e se justaponham, justificando o fato de ser assim hoje e aqui, porque nasci e me criei lá". No que diz respeito à migração para Roraima, o local de origem dos gaúchos variaram bastante: 3 sujeitos migraram de Porto Alegre; 2 de Santa Maria; 2 de Cruz Alta; 1 de Caçapava do Sul; 1 de Frederico Westphalen e 1 de Humaitá. As respostas obtidas quanto ao local de origem, bem como o tempo que os gaúchos entrevistados residem em Roraima foram importantes para uma melhor compreensão e interligação com as demais respostas obtidas, que serão apresentadas na sequência.

Todos os 10 entrevistados responderam que ainda vão ao Rio Grande do Sul passear ou visitar amigos e familiares, destes: 7 sujeitos vão 1 vez ao ano; 1 sujeito vai a cada 3 meses e 2 responderam que vão sempre que possível, em feriados prolongados e folgas do trabalho, entre as respostas destaca-se a do sujeito 5 que respondeu: "Vou sempre que possível, minha filha mais nova e meus pais moram lá, mas meu esposo, duas filhas e netos moram aqui em Roraima, então estou sempre dividida, com um pé lá e outro cá”. O fato de este sujeito vivenciar constantemente diferentes contextos, por exemplo, pode interferir na formação identitária dele, pois de acordo com Woodward (2000, p. 30), "Diferentes contextos sociais fazem com que nos envolvamos em diferentes significados sociais".

Quando questionados se percebem alguma diferença no sotaque e/ou modo de falar quando estão no Rio Grande do Sul do que quando estão em Roraima, 6 entrevistados responderam que percebem diferenças. As respostas foram inusitadas, entre elas destaca-se: Sujeito 4: "Sim, algumas expressões e modo de falar do cotidiano de Roraima já incorporei no meu vocabulário, até mesmo o nome do Estado, quando cheguei aqui eu falava "Rorâima", agora sei que aqui se fala "Roráima”"; Sujeito 5: "Sim, meu sotaque é tão diferente que um taxista queria me enganar em Porto Alegre, achando que eu era turista. Enquanto 4 entrevistados responderam que não percebem diferenças no sotaque ou modo de falar: Sujeito 1: “Não, já misturei os dois sotaques, mas falo do mesmo jeito aqui e lá.”; Sujeito 6: "Não, perdi nada do meu sotaque, posso ter englobado palavras de Roraima, mas meu sotaque ainda é do sul. Quando vou pra lá as pessoas ficam surpresas como em todo esse tempo não perdi o sotaque gaudério”.

Vale salientar que o tempo, o local de origem e a frequência que visitam o Estado podem ter influências nas respostas dos entrevistados, pois entre os sujeitos que responderam perceber mudanças na forma de falar e no sotaque, são em sua maioria os que moram há mais tempo em Roraima e os que migraram de cidades da capital do Estado (Porto Alegre) ou cidades próximas. Dos 4 entrevistados que responderam não perceber mudanças no sotaque ou forma de falar, 3 moram em Roraima há 1 ano e alguns meses, o que justifica não terem 
modificado o sotaque ou mesmo não perceberem esta mudança, além disto estes sujeitos são de cidades mais próximas ao interior do Rio do Grande do Sul, onde o sotaque é por vezes mais forte e impregnado. Destaca-se, contudo, que 1 sujeito (o sujeito 6) que respondeu não perceber mudanças no sotaque ou forma de falar, veio de uma cidade simples do interior do Rio Grande do Sul, mas mora em Roraima há 26 anos, e visita o Rio Grande do Sul a cada 3 meses. O que nos faz questionar até que ponto uma interação com outra cultura, e com outros contextos sociais realmente afetam nossa identidade, ou se isso é particular e varia de sujeito para sujeito.

Os 10 entrevistados responderam que a motivação para migrarem do Rio Grande do Sul para Roraima foi trabalho/emprego, direta ou indiretamente. Destes, 7 sujeitos vieram diretamente para trabalhar, como menciona por exemplo o Sujeito 4: "Passei num concurso público, larguei tudo o que tinha no Sul e vim em busca de melhores oportunidades de vida."; enquanto 3 sujeitos vieram acompanhar familiares que vieram para trabalhar, como cita o Sujeito 2: "No início odiava aqui, vim para acompanhar meus pais que vieram trabalhar, não tive escolha.”. Estas respostas citadas pelos entrevistados são um exemplo, ainda que simplificado, de uma identidade interessada e interesseira destes sujeitos. Pois na busca de melhores condições de vida eles se submeteram ao movimento de desenraizar e enraizar suas vidas, e em alguns casos a de seus familiares, se adaptando conforme o contexto social e algumas relações de negociação e poder. Indo ao encontro com o que aponta Silva (2000, p. 82) "Afirmar a identidade significa demarcar fronteiras, significa fazer distinções entre o que fica dentro e o que fica fora. A identidade está sempre interligada a uma forte separação e distinção, supõem e, ao mesmo tempo, afirmam e reafirmam relações de poder".

No que diz respeito às relações sociais, pode-se observar que a identidade e o léxico possuem uma ligação. Segundo os estudos linguísticos, o léxico é considerado como elemento que permeia e registra por meio das palavras, a relação entre o sujeito e a sociedade. De acordo com Biderman (2001, p. 179), o léxico é "a somatória de toda a experiência acumulada de uma sociedade e do acervo da sua cultura através das idades".

A investigação lexical contribui para a compreensão da cultura, da sociedade, e como forma de construção de uma identidade específica ou regional. A cultura pode também ser expressada e registrada pelo léxico, possibilitando o estudo identitário, e a demonstração de como ocorre o processo do hibridismo nos sujeitos, como é o caso dos gaúchos roraimados.

Partindo desta concepção, ao solicitar aos entrevistados para citar 3 palavras que resumam/apresentam o Rio Grande do Sul e 3 palavras que resumam/apresentam Roraima, e questioná-los sobre quais sentimentos estas palavras trazem a eles, pode-se observar a 
interligação existente entre as relações sociais, culturais e contextuais nas quais os sujeitos estão envolvidos e inseridos. Além disto, algumas palavras foram mencionadas por mais de um sujeito, tornando-se um exemplo "de conjunto de palavras" nas quais os gaúchos roraimados se comunicam e também percebem seu Estado de origem e seu Estado de moradia atual, conforme é possível observar no quadro a seguir.

Quadro 1 - Palavras que resumam/apresentam o Rio Grande do Sul e Roraima

\begin{tabular}{|l|l|l|}
\hline SUJEITO & RIO GRANDE DO SUL & RORAIMA \\
\hline Sujeito 1 & Pinhão; CTG; Chimarrão & Damurida; Rio Branco; Peixe \\
\hline Sujeito 2 & Chimarrão; Churrasco; Vaneira & Índio; Rio Branco; Monte Roraima \\
\hline Sujeito 3 & Inter; Churrasco; CTG & Îndio; Peixe; Rio Branco \\
\hline Sujeito 4 & Inter; Chimarrão; Vaneira & Emprego; Garimpo; Monte Roraima \\
\hline Sujeito 5 & Cavalos; Campos; Chimarrão & Paçoca; Calor; Emprego \\
\hline Sujeito 6 & Churrasco; Chimarrão; "Barbaridade" & Índio; Emprego; Peixe \\
\hline Sujeito 7 & Churrasco; Chimarrão; Quentão & Rios; Peixe; Emprego \\
\hline Sujeito 8 & "Capaz"; "Barbaridade"; Chimarrão & Farinha; Rios; Calor \\
\hline Sujeito 9 & Inter; Chimarrão; "Capaz" & Rios; Tranquilidade; Farinha \\
\hline Sujeito 10 & Tradicionalista, Multicultural; Lindo & Quente; Bela; Organizada \\
\hline
\end{tabular}

Fonte: elaboração própria com base nas respostas dos entrevistados.

No total de 60 palavras mencionadas pelos 10 entrevistados para resumir/apresentar o Rio Grande do Sul e Roraima algumas se destacaram por serem citadas mais de uma vez. No que diz respeito ao Rio Grande do Sul, os gaúchos roraimados citaram: Chimarrão (8 vezes); Churrasco (4 vezes); Internacional - Inter (3 vezes); Centro de Tradições Gaúchas - CTG (2 vezes); Vaneira (2 vezes); "Barbaridade" - "Bah" (2 vezes); "Capaz" - (2 vezes); pinhão, cavalos; campos; quentão; tradicionalista; multicultural e lindo (1 vez cada respectivamente). Pode-se observar que os gaúchos roraimados associam o Rio Grande do Sul à: bebidas (chimarrão e quentão); comidas (churrasco e pinhão); time de futebol (Internacional); o espaço do CTG e a vaneira (dança típica gaúcha) que ocorre nos CTG's; associam também à expressões como "Barbaridade - Bah" que é comumente utilizada pelos gaúchos para expressar sentimentos e reações; assim como a expressão "Capaz" que serve para confirmar, negar ou ironizar algo. Os entrevistados citam também: cavalos (animais) e campos (espaço aberto, fazenda, chácara) que são geralmente vistos no interior do Estado; além disto o sujeito 10 resume o Rio Grande do Sul com as palavras "Tradicionalista, Multicultural e Lindo", o que mostra uma visão mais generalizada e ampla deste sujeito, diferentemente dos demais.

Quanto às palavras que resumem/apresentam Roraima, as citadas pelos gaúchos roraimados foram: Peixe (4 vezes); Emprego (4 vezes); Rio Branco (3 vezes); Índio (3 vezes); Calor (3 vezes); Rios (3 vezes); Farinha (2 vezes); Monte Roraima (2 vezes); damurida; garimpo; paçoca; tranquilidade; bela e organizada (1 vez cada respectivamente). Assim, pode- 
se observar que os gaúchos roraimados associam Roraima à: comida (farinha, paçoca, peixe e damurida); emprego; lugares (Rio Branco, Rios e monte Roraima); ao indígena (Índio); as altas temperaturas (calor); ao garimpo; e a tranquilidade , beleza e organização.

Quanto aos sentimentos que as palavras citadas despertaram nos entrevistados, as respostas variaram bastante, em sua maioria os entrevistados sentiram-se saudosos aos falar do Rio Grande do Sul, e contentes e acolhidos ao falar de Roraima, entre as respostas destacase: Sujeito 2: "O Rio Grande do Sul me traz um sentimento de uma cultura sólida, forte que me marca por meio de sua comida e danças das quais tenho muita saudade. E por Roraima tenho sentimento de acolhimento, liberdade e oportunidade”. Sujeito 3: "Os dois lugares me trazem bons sentimentos, o Rio Grande do Sul com meu time de futebol, o Internacional, que é um amor sem explicação, com a comida e seus espaços de cultura e música que sempre gostei muito e em Roraima me sinto acolhida". Sujeito 4: "Sinto muitas saudades do Rio Grande do Sul, do frio; da música. Roraima supre um pouco essa saudade com o CTG, aqui sinto hospitalidade; tranquilidade; oportunidade e calor”. Sujeito 6: "O Rio Grande do Sul me traz sentimentos de amor; frio e força por vir de lá; e Roraima me sinto no meio de uma mistura de gente, acho que o sentimento que mais percebo aqui é o de acolhimento, todo mundo é bem-vindo."

Estas palavras e estes sentimentos que os gaúchos roraimados expressaram, demonstram claramente sujeitos com identidades híbridas, que têm a concepção de elementos da cultura da região da qual estão inseridos atualmente, mas sem deixar de lado os elementos da cultura de sua região de origem. O hibridismo, conforme Silva (2000, p. 87), "Está ligado aos movimentos demográficos que permitem o contato entre diferentes identidades", como é o caso apresentado dos gaúchos roraimados entrevistados.

Ainda quanto à identidade e o hibridismo que a envolve, outro exemplo que se destaca, foi obtido ao questionar os entrevistados sobre a cultura que mais se identificam atualmente. Dos 10 entrevistados: 7 sujeitos responderam se identificar com ambas as culturas; 1 sujeito citou ambas, mas mais a Roraimense, 1 sujeito afirmou se identificar apenas com a cultura Rio Grandense e 1 sujeito disse se identificar com ambas e mais algumas. As respostas foram bem inusitadas. Entre elas destaca-se: Sujeito 2: “Ambas, tem coisas que gosto e que não gosto nas duas. Do Rio Grande do Sul gosto do tradicionalismo, das danças, das comidas, mas em sua maioria são pessoas frias, metidas e arrogantes. Já em Roraima o povo é acolhedor e receptivo, mas, ao mesmo tempo, é uma terra de ninguém, todo mundo é bem-vindo, deixando um pouco bagunçado o Estado.”; Sujeito 5: “Ambas, mas atualmente me identifico mais com a cultura roraimense, porque me parece ser mais humana, 
com uma sociedade diversa, solidária e desbravadora em todos os sentidos.”; Sujeito 6: "Mesmo morando aqui há 13 anos me identifico com a cultura Rio Grandense, pois hoje ainda é muito forte nos meus hábitos. ”; “ Sujeito 10: “Ambas e mais algumas, já morei em onze lugares diferentes e acredito que assimilei um pouquinho da cultura de cada lugar. A raiz continua Sul-rio-grandense, mas Roraima e os outros lugares que já morei vão sempre ocupar um espaço no meu coração."

Indo ao encontro com estas respostas obtidas, Silva (2000, p. 85) aponta que "É necessário criar laços imaginários que permitam "ligar" pessoas que, sem eles, seriam simplesmente indivíduos isolados, sem nenhum "sentimento" de terem qualquer coisa em comum". Desta forma, todas as respostas, mesmo que divergentes, se justificam, pela necessidade de se firmar identitariamente, ou pela necessidade do sentimento de pertencimento que os sujeitos têm, seja na cultura Rio Grandense, Roraimense ou em ambas.

\section{Considerações finais}

O presente artigo mostrou aspectos acerca da identidade de 10 gaúchos que moram em Roraima no período entre 29 anos à 1 ano e 4 meses, migrados de diversas cidades do Rio Grande do Sul, que vieram à Roraima em busca de melhores empregos e condições de vida. Foi possível observar que o tempo e o espaço tiveram influência na identidade dos gaúchos roraimados.

Ao apresentar os diferentes pontos de vista acerca do seu sotaque; o léxico por meio de diversas palavras e expressões que representam seu Estado de origem e o atual; seus sentimentos; e diferentes identificações culturais, foi possível perceber que a identidade dos gaúchos roraimados é: interessada, interesseira e torna-se e interessante de ser estudada, por ser um exemplo prático de como ocorre o hibridismo identitário.

Ao observarmos o hibridismo identitário por meio da ótica teórico-prática foi possível ter uma melhor compreensão de como ele ocorre nos sujeitos. Sendo que o estudo teórico embasou e fundamentou o prático. Ao aliar a teoria com as respostas obtidas, foi possível constatar que a identidade dos gaúchos roraimados é constituída por uma série de fatores que a influenciam, entre eles: a linguagem, a língua, o léxico, as relações sociais, culturais, de poder, de negociação com os outros e consigo mesmo, o sentimento de pertencimento; a concepção da diferença, entre outros.

Além disto, foi possível observar ao longo da análise das respostas obtidas que consciente, ou inconscientemente os gaúchos roraimados possuem a percepção de sua identidade híbrida quando, por exemplo, em sua maioria, eles afirmam que acreditam 

e-ISSN 2016/Atual: 2525-7870 | e-ISSN 2015/2016: 2447-018X

pertencer e identificar-se com ambas as culturas, a Rio Grandense e Roraimense, adotando em suas vidas palavras, costumes e aspectos particulares de cada uma, tornando-se assim sujeitos com identidades multifacetadas.

Vale salientar que este tema merece ser estudado mais a fundo, investigando, por exemplo, a influência individual dos fatores mencionados na identidade, ou seguindo esta mesma linha de estudo, contemplando um maior número de sujeitos roraimados. Comparando, por exemplo, a percepção de identidade, destes 10 gaúchos investigados, com a percepção de 10 maranhenses, 10 Paraíbanos, etc, englobando demais sujeitos que migram de diferentes estados para Roraima.

\section{Referências}

BAUMAN, Z. O mal-estar da pós-modernidade. Rio de Janeiro: Zahar, 1998. Identidade. $1^{\circ}$ ed. Rio de Janeiro: Jorge Zahar Editor, 2005.

BHABHA, H. O local da cultura. Belo Horizonte: UFMG, trad. Myriam Ávila, Eliana Reis, Gláucia Gonçalves, $4^{\mathrm{a}}$ reimpressão, 1987.

BIDERMAN, M. T. C. Teoria linguística: teoria lexical e linguística computacional. São Paulo: Martins Fontes, 2001.

BOTELHO, S. M. de P. D. Escola Técnica de Roraima: retrospectiva da trajetória de desenvolvimento através da memória. Dissertação de Mestrado (Mestrado em Educação). Universidade Federal do Amazonas (UFAM), 2009.

CANClini, N. G. Culturas híbridas. Tradução de Ana Regina Lessa e Heloísa Pezza Cintrão. São Paulo: Edusp, 1997.

CÉSAR, A. L. \& CAVALCANTI, M. C. Do singular ao multifacetado: o conceito de língua como caleidoscópio. In: M. C. Cavalcanti \& Bortoni - Ricardo (orgs.). Transculturalidade, linguagem e educação. Campinas, SP: Mercado das Letras, 2007.

FREITAS, D. B. A. P. A construção do sujeito nas narrativas orais. In CLIO. Revista de Pesquisa Histórica. N. 25-2, 2007. Recife: Ed. Universitária da UFPE. 2008.

HALL, S. A identidade cultural na pós-modernidade. Trad. T. T. da Silva, G. L. Louro. Rio de Janeiro: DP\&A, 2006.

INSTITUTO BRASILEIRO DE GEOGRAFIA E ESTATÍSTICA - IBGE. Disponível em: <www.ibge.gov.br >. Acesso em: 11 de Jan. 2017.

LAGARES, X. C. Identidade e (in)definição linguística: galego e/ou português. In: L. P. da Moita Lopes \& L. C. Bastos (orgs). Para além da identidade: fluxos, movimentos e trânsitos. Belo Horizonte: Editora UFMG, 2010. 
LUVIZOTTO, C. K. Cultura gaúcha e separatismo no Rio Grande do Sul. São Pauᄀlo: UNESP, 2009. Disponível em: <http://static.scielo.org/scielobooks/kkf5v/pdf/luvizotᄀto9788579830082.pdf>. Acesso em: 22 Out. de 2016.

NEVES, J. L. Pesquisa qualitativa - características, uso e possibilidades. Cadernos de pesquisa em administração. São Paulo. V. 1, nº 3, $2^{\circ}$ sem, 1996.

SILVA, T. T. A produção social da identidade e da diferença. In: T.T. da Silva (Org.). Identidade e diferença: a perspectiva dos estudos culturais. Petrópolis: Vozes, 2000.

SOUZA. C. M. Gaúchos em Roraima: memória, regionalismo e identidade. Disponível em: <http://revistaseletronicas.pucrs.br/ojs/index.php/iberoamericana/article/view/1310/1015>. Acesso em: 23 Out. de 2016.

VILELA, M. Léxico e gramática. Coimbra: Almedina, 1995.

XAVIER, A. C. CORTEZ, S. (orgs). Conversas com linguistas: virtudes e controvérsias da linguística. São Paulo: Parábola Editorial, 2003.

WOODWARD, K. Identidade e diferença: uma discussão teórica e conceitual. In: T.T. da Silva (Org.). Identidade e diferença: a perspectiva dos estudos culturais. Petrópolis: Vozes, 2000. 